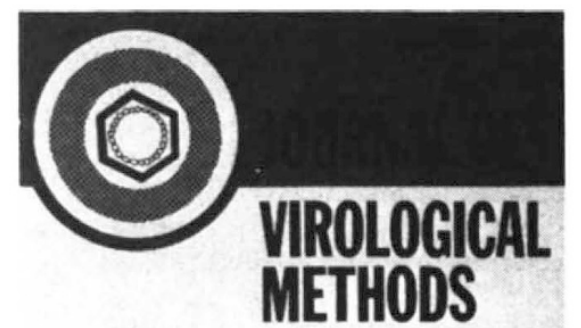

within the purview of the JVM - titles involving radioimmune assay, immune electron microscopy and monoclonal antibodies abound on the contents' page. Perhaps surprisingly, some of the papers would seem to have little specifically medical connection.

The two journals are well produced with illustrations of high standard. Virologists will undoubtedly wish to persuade their librarians to give both of them a run, although in the nowadays inevitable assessment of priorities are likely to be reluctant to substitute the JVM for the red, blue or yellow journals. The medical virologist has an even more difficult choice between the JMV and others covering bacteriology and immunology as well as medical virology. Nevertheless, papers so far published in this journal seem well up to the standard in the others and the willingness of many of, the authors to incorporate molecular techniques into their work must surely be a welcome development.

D.H. Watson is Professor of General Microbiology and Head of the Department of Microbiology at the University of Leeds. He is a former Editor-in-chief of the Journal of General Virology.

\title{
The Current Ferment in Publishing
}

\section{Stephen Oliver}

Plasmid. Editor-in-chief R.P. Novick. $6 / \mathrm{yr}$ in 2 vols. (Academic.) 1981: $£ 50 \mathrm{UK}$, $\$ 98$ elsewhere. Biotechnology Letters. Editor-in-chief J.D. Bu'Lock. 12/yr. (Science and Technology Letters, Kew, Surrey, UK.) £58. Current Microbiology. Editor M.P. Starr. 6/yr. (SpringerVerlag.) DM128. Current Genetics. Managing editor F. Kaudewitz. $6 / \mathrm{yr}$ in 2 vols. (Springer-Verlag.) DM276.

THERE are two good reasons for starting a new journal. The first is that you have identified a new subject area which requires more concentrated coverage or a different type of approach than that provided by the existing literature. The second is that your present journal is so successful that it is oversubscribed with good quality papers for which a new outlet is required. Plasmid and Biotechnology Letters (BL) come into the first category, while Current Microbiology (CM) and Current Genetics (CG) are both the offspring of established journals.

Plasmid is designed to provide a forum for research on extrachromosomal genetics. It is the only one of the four journals which uses conventional refereeing procedures, yet publication delays are by no means bad; papers appear four to six months after acceptance, although due to revisions this usually means $c$, nine months after the original submission date. Full papers and short communications are published, and also "short, critical, highly-focussed" reviews. The latter have been of particularly high quality and it seems appropriate that a new journal which contributes to the burden of an everexpanding literature should also attempt to distil and clarify information in its area. Plasmid also carries announcements of interest to readers as well as abstracts, and even full articles, from specialized meetings.

The attraction of Plasmid is that it deals with extrachromosomal genetic systems in all organisms from $E$. coli to human beings. One therefore finds papers on bacterial plasmids together with work on mitochondrial and chloroplast genetics in higher plants and animals. The quality of papers is high and the journal is a worthwhile one, even though workers in this area tend to reserve their major advances for publication in such high-impact journals as Nature, Cell and the Proceedings of the National Academy of Sciences.

It may seem remarkable to some that Biotechnology Letters can function at all when it often appears that anyone with a genuinely good idea in this area first telephones his patent lawyer and then contacts a merchant banker. Nevertheless, it seems to have found a distinct and valuable role. BL is a rapid publication journal which publishes short communications from camera-ready manuscripts. Publication time is certainly short - about six weeks from submission. Indeed, the early issues even managed to include some articles received after the publication date.

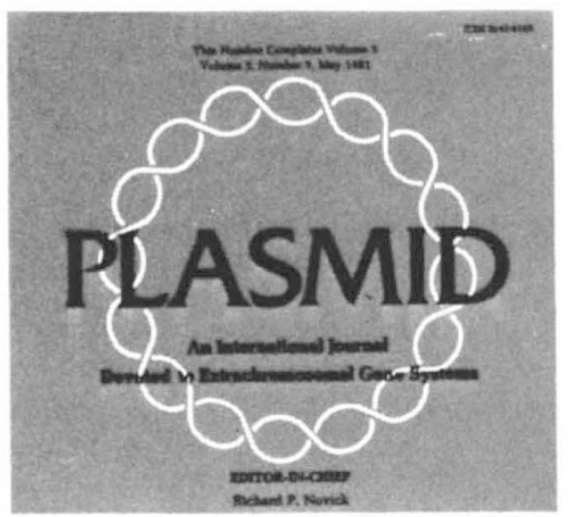

Contributions are submitted directly to members of the editorial board which is composed of chemical engineers, microbial physiologists and microbial biochemists. The content of the articles reflects these interests as well as more peripheral topics, such as one discussion of patent law. BL is a lively and interesting journal which also includes a detailed calendar of relevant meetings and a monthly editorial. The latter is generally written by the chief editor, but is occasionally produced by a guest. The editorial usually takes an evangelical form with not infrequent sideswipes at government. However, this is preaching to the converted and I suspect the Whitehall (or Washington) mandarins don't read it - perhaps they should.

$\mathrm{CM}$ is a journal which has yet to find a distinct role. Like its forebear, Archives of Microbiology, it covers the whole of microbiology. There is, then, nothing to distinguish it from Archives, except the fact that the quality of papers in the parent journal is probably higher. $\mathrm{CM}$ claims to be a rapid publication journal, producing papers eight weeks after their acceptance. This claim is hard to judge when the journal appears without a publication date for itself or receipt dates for its papers. It is reported, however, that refereeing procedures are extremely slow. It may have been more sensible to expand Archives and accelerate its publication of short communications, rather than spawn this new journal.

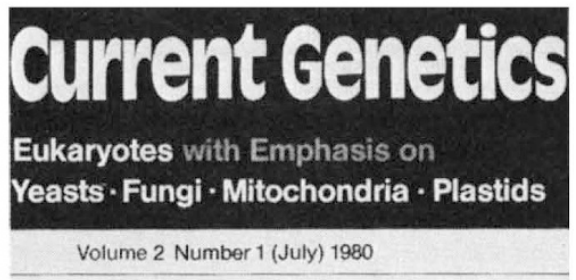

In contrast, $\mathrm{CG}$ has successfully hived off a particular area from its parent journal, Molecular and General Genetics. It deals with eukaryotic genetics and emphasizes yeasts, the filamentous fungi, mitochondria and chloroplasts. Preference is given to papers with a molecular bias; they should also merit urgent publication. It takes $c$. six months for a paper to appear in $\mathrm{CG}$, which is about average for a bimonthly journal and hardly qualifies as "urgent". Three-quarters of the editorial board of the journal work on yeasts and at least half the papers deal with Saccharomyces genetics. Yeast genetics is developing rapidly at present and many fundamental advances are being made with this organism. This makes CG a journal which is truly "current" and of high quality. In the long term it remains to be seen whether it can change its focus, and survive, if interest in yeast should wane. For the moment, however, it is riding high.

Stephen Oliver is in the Applied Molecular Biology Group at the University of Manchester Institute of Science and Technology. 